International Journal of Current Advanced Research

ISSN: O: 2319-6475, ISSN: P: 2319 - 6505, Impact Factor: SJIF: 5.995

Available Online at www.journalijcar.org

Volume 6; Issue 5; May 2017; Page No. 3604-3606

DOI: http://dx.doi.org/10.24327/ijcar.2017.3606.0328

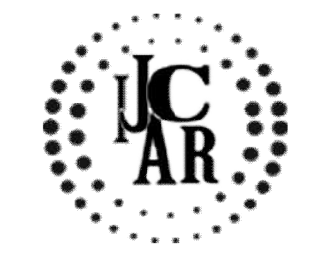

Research Article

\title{
EVALUTION OF POSTERIOR SEGMENT OF EYE ON B- SCAN USG
}

\author{
Pawan N. Jarwal., Kinjal H. Desai., Anjali Kavthekar and Ganvit S.S
}

Department of Ophthalmology, Baroda Medical College and SSG hospital, Vadodara.390001

\section{A R T I C L E I N F O}

\section{Article History:}

Received $17^{\text {th }}$ February, 2017

Received in revised form $12^{\text {th }}$ March, 2017

Accepted $2^{\text {nd }}$ April, 2017

Published online $28^{\text {th }}$ May, 2017

Key words:

Ultrasonography, B scan,

Ophthalmology.

\begin{abstract}
A B S T R A C T
Purpose: This study is done to evaluate the role of B-Scan in patients with corneal opacity, bullous keratopathy and anterior staphyloma. For knowing status of posterior segment in cases of traumatic hypheama, in case of dislocation of lens, in cases of occlusiopupillae, cataract and leukocoria via B Scan. For assessing cases of vitreous haemorrhagefor diagnosing retinal detachment and intra ocular tumour. For accurate localization of intraocular foreign bodies. Materials and Method: This is prospective study of 50 cases of patients with posterior segment abnormalities on B-Scan. Ultrasonic tissue density is known by focusing an echo on screen and then gradually decreasing sensitivity control till that echo disappear.Mobiliy of ultrasound abnormality is tested by asking the patient to move eyes while the probe is held stationary. Results: Cases with Corneal Opacity showed RD, VH, Dislocated IOL, Endophthalmitis and CD.Cases of Anterior Staphyloma showed VH with RD and RD. Cases of Traumativ Hyphema showed VH, VH with PVD, VH with PVD with Aphakia and FB in vitreous cavity. Cases of Occlusio Pupillae showed VH and Endophthalmitis. Conclusion: As utilized in ophthalmology, ultrasound both complement and surpasses the capabilities of other diagnostic technique in the evaluation of abnormalities, particularly those produced by ocular and orbital tumours, vitreous hemorrhage, trauma and foreign bodies.
\end{abstract}

Copyright $(2017$ Pawan N. Jarwal et al. This is an open access article distributed under the Creative Commons Attribution License, which permits unrestricted use, distribution, and reproduction in any medium, provided the original work is properly cited.

\section{INTRODUCTION}

The medical use of ultrasound, in only a score of years, has reached the point where it is now universally regarded as an essential means of soft tissue examination in the eye. Within the last decade B Scan screening of the opaque ocular media, particularly in the eye with cataract and vitreous hemorrhage has constituted the two most common indication for ocular ultrasound examination. Furthermore the echo graphic examination of intraocular lesions even if they are clearly visible on fundoscopy has become an essential component in the differentiation of many ocular disease such as intraocular tumors, leukocorias, macular lesion, optic disc abnormalities and choroidal folds. As utilized in ophthalmology, ultrasound both complement and surpasses the capabilities of other diagnostic technique in the evaluation of abnormalities, particularly those produced by ocular and orbital tumours, vitreous hemorrhage, trauma and foreign bodies. Ultrasound by providing this increased diagnostic potential, has modified the treatment of many ophthalmic problem.

\section{MATERIALS AND METHODS}

This is prospective study of 50 cases of patients with posterior segment abnormalities on B-Scan.

\section{*Corresponding author: Pawan N. Jarwal} Department of Ophthalmology, Baroda Medical College and SSG hospital, Vadodara.390001
The criteria of selection of patients were 1) Cases of Opaque media like corneal opacities, hyphaema, hypopyon, cataract and occlusio pupillae2) Cases of Clear media like choroidal and retinal detachment, vitreoushemorrhage and suspected tumours 3) Blunt/Penetrating trauma to eye 4) Intraocular foreign body.

All the cases were studied on Sonoline 2 machine with 7.5 $\mathrm{MHz}$ probe or with $10 \mathrm{MHz}$ probe. $1 \%$ methylcellulose is applied to the surface of the probe and gentle contact is made against the closed lids. The three basic probe orientations which were used are Axial, Transverse and Longitudinal. Routine examination include an axial length view of globe demonstrating posterior portion of lens and optic nerve. Rest of the examination is performed from a position behind the iris-lens diaphragm, thus avoiding the artifacts induced by lens.

Ultrasonic tissue density is known by focusing an echo on screen and then gradually decreasing sensitivity control till that echo disappear.Mobiliy of ultrasound abnormality is tested by asking the patient to move eyes while the probe is held stationary. 


\section{RESULTS AND ANALYSIS}

Age Distribution of Cases

\begin{tabular}{ccc}
\hline Years & Number & $\mathbf{\%}$ \\
\hline $0-10$ & 5 & 10 \\
$11-20$ & 8 & 16 \\
$21-30$ & 6 & 12 \\
$31-40$ & 7 & 14 \\
$41-50$ & 5 & 10 \\
$51-60$ & 9 & 18 \\
$>60$ & 10 & 20 \\
Total & 50 & \\
\hline
\end{tabular}

As seen from above, there is no particular age group more likely to present for USG of eye

\section{Clinical Presentation}

\begin{tabular}{ccc}
\hline Clinical feature & Number & $\mathbf{\%}$ \\
\hline Trauma & 21 & 42 \\
Diminision of vision & 23 & 46 \\
Pain & 4 & 8 \\
Deviation of eye & 1 & 2 \\
Floaters & 1 & 2 \\
Total & 50 & \\
\hline
\end{tabular}

In this series of study the most common form of presentation was dimness of vision. Next to this patients were presenting with the complain of trauma.

\section{Distribution of Sonographic Lesion}

\begin{tabular}{ccc}
\hline Lesion & Number & $\mathbf{\%}$ \\
\hline Lens & 6 & 12 \\
Vitero-Retinal & 38 & 76 \\
Foreign bodies & 3 & 6 \\
Choroid & 3 & 6 \\
TOTAL & $\mathbf{5 0}$ & \\
\hline
\end{tabular}

As we see maximum number of patients were in group of vitreo-retinal lesion.

\section{Distribution of Vitreoretinal Lesion}

\begin{tabular}{ccc}
\hline & Number & \% \\
\hline VH & 10 & 26.31 \\
VH with PVD & 03 & 7.89 \\
VH with RD with PVD & 05 & 13.15 \\
RD & 12 & 31.57 \\
RD with Fundal Coloboma & 01 & 2.63 \\
Retinoblastoma & 03 & 7.89 \\
Endophthlamitis & 03 & 7.89 \\
RD with CD & 01 & 2.63 \\
Total & 38 & \\
\hline
\end{tabular}

\section{Distribution of Lens Lesion}

\begin{tabular}{ccc}
\hline & Number & $\mathbf{\%}$ \\
\hline $\begin{array}{c}\text { Dislocation with } \\
\text { vitreous bands }\end{array}$ & 1 & 16.66 \\
$\begin{array}{c}\text { Dislocation with PVD } \\
\text { Aphakia with PVD }\end{array}$ & 3 & 50 \\
with PCO & 1 & 16.66 \\
Aphakia with VH with & 1 & 16.66 \\
PVD & 6 & \\
TOTAL & \\
\hline
\end{tabular}

\section{Analysis}

In Patients with Corneal Opacity

\begin{tabular}{ccc}
\hline B-Scan finding & NUMBER & $\mathbf{\%}$ \\
\hline RD & 5 & 45.45 \\
VH & 2 & 18.18 \\
Dislocated lens with PVD & 1 & 9.09 \\
Dislocated IOL & 1 & 9.09 \\
Endophthlmitis & 1 & 9.09 \\
CD & 1 & 9.09 \\
TOTAL & 11 & \\
\hline
\end{tabular}

\section{In Patients with Anterior Staphyloma}

\begin{tabular}{ccc}
\hline B-Scan finding & Number & $\mathbf{\%}$ \\
\hline VH and RD & 1 & 33.33 \\
RD & 2 & 66.66 \\
Total & $\mathbf{3}$ & \\
\hline
\end{tabular}

In Patients with Hyphaema

\begin{tabular}{ccc}
\hline B-Scan finding & Number & $\mathbf{\%}$ \\
\hline VH & 3 & 42.85 \\
VH with PVD & 1 & 14.48 \\
VH with PND with & 1 & 14.28 \\
Ahakia & 1 & 14.28 \\
VH with IOFB & 1 & 14.28 \\
IOFD & 7 & \\
Total &
\end{tabular}

In Patients with Cataract

\begin{tabular}{ccc}
\hline B-Scan finding & Number & $\mathbf{\%}$ \\
\hline VH & 1 & 25 \\
RD & 1 & 25 \\
RD with PVD & 1 & 25 \\
Aphakia with dense & 1 & 25 \\
PCO with PVD & 4 & \\
TOTAL & 4 \\
\hline
\end{tabular}

In Patients with Occulusio Pupillae

\begin{tabular}{ccc}
\hline B-Scan finding & Number & \% \\
\hline VH & 1 & 33.33 \\
Endophthalmitis & 2 & 66.66 \\
TOTAL & $\mathbf{3}$ & \\
\hline
\end{tabular}

In Patients with Intraocular Mass

\begin{tabular}{ccc}
\hline B-Scan finding & Number & $\mathbf{\%}$ \\
\hline RB & 1 & 50 \\
Choroidal melanoma & 1 & 50 \\
with RD & $\mathbf{2}$ & \\
TOTAL &
\end{tabular}

\section{DISCUSSION}

In this study patients with $\mathrm{VH}$, occlusio pupillae, $\mathrm{RD}$, anteriorstaphyloma, cornealopacity, traumatic hyphaema, cataract, CD, leukocoria and mass which were diagnosed on gross examination were subjected to B-Scanning. The aim of sonography was to rule out the possibility of associated poor segment abnormality. Ruling out posterior segment abnormality is a must prior tosurgical intervention for anterior segment pathology as removing the anterior segment pathology alone would not give vision to the patient.

All the patients with anterior staphyloma studied had Post. Segment abnormality in form of RD and VH. So, staphylectomy with keratoplasty was indicated in these patients only for cosmetic purpose.

In patients with corneal opacity with RD conservative line of management was done whereas in those with corneal opacity and subluxated lens and IOL, lens removal with keratoplasty at a later date or in same sitting was indicated. In patients with corneal opacity and $\mathrm{VH}$, conservative line of management was adopted.

Patents with cataract and fresh RD were indicated for cataract extraction followed by RD surgery whereas those with long standing RD were contraindicated for surgery. Patents with hyphaema and $\mathrm{VH}$ were treated conservativelywhereas those with hyphaema and IOFB were subjected to surgery. Simple cases with just VH were treated on servatively whereas those having $\mathrm{RD} / \mathrm{IOFB}$ were subjected for surgery. Sonography 
plays a very important role in study of VITREO-RETINAL status. The echo poor vitreous is agreat boon to the sinologist as all lesion of the vitreous are echogenic. OF the 50 patients in this studies, 47 had vitreo-retinal lesion. Out of 47 vitreo retinal lesion $80.85 \%$ were primary vitreo retinal lesion whereas in the rest of $19.14 \%$ cases main site of lesion was somewhere else. $12.76 \%$ had main lesion in lens, $4.25 \%$ had main lesion in form of IOFB whereas $2.12 \%$ had main lesion in the form of choroidal melanoma. In one study carried out by Coleman of 100 patients, he found that the largest group comprising of 37 patients was that of RD [3]. In this study of 50 patients, 20 had RD.

Patients with RD were subjected to B- Scanning for 2 principal reasons; 1) Eye was not visualized due to opaque media. 2) Question of tumours behind RD in patients with clear media the earliest detachment to be recognized is the total RD. In case of localized RD it may be difficult to discern from choroidal elevation, thickened PVD and small melanomas.

Another common condition seen in the vitreous is VITREOUS HAEMORRHAGE. B scan in case of $\mathrm{VH}$ is mainly indicated to rule out presence of RD, tumours, FB, and dislocated lens behind the hemorrhage. Sonography however can identify certain aspects of hemorrhage. In this study a total of $44 \%$ cases had $\mathrm{VH}$ out of which $9.09 \%$ had IOFB, $13.63 \%$ had RD, $13.63 \%$ had RD with PVD, $13.63 \%$ had PVD, and 4.54 had Aphakia with VH with PVD while $45.4 \%$ had just $\mathrm{VH}$.

The common INTRAOCULAR TUMOURS are choroidal melanoma, retinoblastoma, secondaries and hemangiomas. These can be differentiated on the basis of tissue characterization and amplitude pattern. Due to high reliability of ultrasonographyin detecting and identifying intraocular tumours and the noninvasive nature of sonography, USG is recommended in all patients with suspected tumours. In this study $8 \%$ cases had intraocular tumours out of which $75 \%$ had $\mathrm{RB}$ and $25 \%$ had choroidal melanoma.

IN TRAUMA, USG is used to assess ocular damage if the media are opaque after blunt or penetrating injury. In eyes with retained foreign material, USG may also be used to aid localization of the foreign body. In our study $42 \%$ of patients were post traumatic, out if which $23.80 \%$ patents had lesion in form of cataract, subluxation, post. Dislocation, lens absorption $61.90 \%$ of patients had vitreo retinal lesion in form of VH, PVD, RD and $14.28 \%$ of patients had IOFB.

\section{CONCLUSION}

Ultrasonography is very useful for knowing;

1. Status of posterior segment in anterior segment pathologies.

2. For knowing status of retina in cases of vitreous hemorrhages.

3. In cases of retinal detachment to know the etiology of retinal detachment (primary or secondary)

4. For diagnosis of intraocular mass

5. For accurate localization of IOFB

Ultrasonography in the pathologies of vitreous and retina scores over all other modalities.it has a unique role in patients with trauma. It helps to know status of vitreous and retina and helps in accurate localization of IOFB. Ultrasonography is superior to X-rays in detecting IOFB in a way that X-rays detect radiopaque FB whereas USG detects any FB. Ultrasonography is very helpful in differentiation of intraocular tumour.

The unique dynamic quality of ultrasound imaging allows the depiction of vascular and pulsatile lesions and the effect of ocular movements on normal and abnormal orbital structures.

\section{References}

1. Coleman DJ, Lizzi FL, Jack RL. Ultrasonography of eye and orbit. Philadelphia, Lea and Fibiger, 1977.

2. Atta HR. OphthalmicUltrasound; APractical Guide. London, Churchill Livingstone, 1996.

3. Baum Greenwood I. The application of Ultrasonic locating technique to ophthalmology. Am J Ophthal 1958, 46:319.

4. Cheremesin V.M. et.al. Ultrasonography in combined modality diagnosis of intraocular tumours. Vestn Rentgenol Radiol. 1991 Nov-Dec; 50-6.

5. D. Jackson Coleman.Relaibility of ocular and orbital diagnosis with B-Scan ultrasound. AM J of Ophthal, APRIL, 1972.

6. Pavlin C.J .et.al. Clinical use of Ultrasound Biomicroscopy. Ophthalmology 1991 Mar; 98(3):28795.

7. Yale L. Fisher. Ultrasonography "Principle and Practice of Ophthalmology-Peyman, Sanders, Goldberg”, 1987; 1402-87.

\section{How to cite this article:}

Pawan N. Jarwal et al (2017) ' Evalution Of Posterior Segment Of Eye On B- Scan Usg', International Journal of Current Advanced Research, 06(05), pp. 3604-3606.

DOI: http://dx.doi.org/10.24327/ijcar.2017.3606.0328 